\title{
High Spatial Density 6-Mode 7-Core Fiber Amplifier for L-band Operation
}

\author{
Yongmin Jung, Senior Member, IEEE, Masaki Wada, Kohki Shibahara, Member, IEEE, Saurabh Jain, \\ Ian A. Davidson, Pranabesh Barua, John R. Hayes, Taiji Sakamoto, Takayuki Mizuno, Member, IEEE, \\ Yutaka Miyamoto, Member, IEEE, Yusuke Sasaki, Kunimasa Saitoh, Member, IEEE, Kazuhide \\ Nakajima, Member, IEEE, and David J. Richardson, Fellow, IEEE, Fellow, OSA
}

\begin{abstract}
We present a high spatial density space division multiplexed fiber amplifier (i.e. 6-mode 7-core multicore fiber amplifier) supporting 42 spatial channels. A high average modal gain of $23.1 \mathrm{~dB}$ is obtained in the $L$-band with an average differential modal gain of $3.2 \mathrm{~dB}$ and a minimum output power of $17.5 \mathrm{dBm}$ per core per mode. The total power consumption of the amplifier is improved by a power reduction factor of 0.36 and a fully fiberized optical amplifier is realized in a cladding-pumped configuration. The assembled amplifier is then tested in a fewmode multicore fiber transmission link and simultaneously amplified 42 spatial channel fiber transmission is demonstrated with the highest spatial density and energy efficiency to date.
\end{abstract}

Index Terms - Fiber optics and optical communications, Fiber devices and optical amplifiers, Space division multiplexing, Few mode fiber and multicore fiber amplifier

\section{INTRODUCTION}

$\mathrm{F}$ EW mode multicore fibers (FM-MCFs) have attracted considerable attention in the research community as a means to increase the information capacity of space division multiplexed (SDM) transmission systems [1-4], with spatial channel multiplicities $>100$ already successfully demonstrated [5-7]. In order to realize long distance SDM transmission, the matching amplifiers, i.e. few-mode multicore fiber amplifiers, need to be developed. Recently, there have been two reports of such FM-MCF amplifiers. The first demonstration was of a 3mode 6-core fiber amplifier supporting 18 spatial channels in a cladding pumped configuration [8] and the other was of a 3mode 7-core fiber amplifier supporting 21 spatial channels in a core pumped implementation [9]. The spatial multiplicities

Manuscript received November 6, 2019. This work was supported in part by the UK EPSRC funded "Airguide Photonics" Programme Grant (EP/P030181/1) and NICT, Japan, as part of the "Innovative Optical Fibre and Communication Technology for Exa-bit Era with SDM" program. Data contained in this paper is openly available from the University of Southampton repository at http://dx.doi.org/10.5258/SOTON/XXXXXX.

Y. Jung, S. Jain, I. A. Davidson, P. Barua, J. R. Hayes, D. J. Richardson are with the Optoelectronics Research Centre, University of Southampton, Southampton, SO17 1BJ, U.K. (e-mail: ymj@orc.soton.ac.uk, sj3g11@orc.soton.ac.uk, i.a.k.davidson@soton.ac.uk, p.barua@soton.ac.uk, jrh@orc.soton.ac.uk, djr@orc.soton.ac.uk).

M. Wada, T. Sakamoto, K. Nakajima are with the NTT Access Network Service Systems Laboratories, NTT Corporation 1-7-1, Hanabatake, Tsukuba, Ibaraki, Japan (e-mail: masaki.wada.zg@hco.ntt.co.jp, taiji.sakamoto.un@hco.ntt.co.jp, kazuhide.nakajima.gr@hco.ntt.co.jp). achieved to date whilst impressive are still relatively modest compared to what has been achieved in the transmission fibers themselves, and substantial improvements in both multiplicity and performance should be possible and are worthy of further study. In addition, these SDM amplifiers have been recently realized in a fully fiberized format. For example, a fully integrated 32-core MCF amplifier [10] has been demonstrated in a cladding pumped configuration with the aid of two key SDM fiber components (i.e. an integrated SDM isolator [11] and a side pump coupler [12]). The side pump coupler allows low-cost multimode pump radiation to be coupled into the active fiber and hence the SDM amplifier to be directly spliced to its matching transmission fiber. The two fully integrated SDM isolators can be incorporated at both the input and the output ends of the amplifier to simultaneously suppress unwanted back-reflections into the amplifier. Such fully integrated SDM amplifiers have great potential for reducing the cost/space/energy per transmitted bit compared to a parallel array of single mode fiber amplifiers and the FM-MCF amplifiers can help maximize these benefits in a most efficient manner.

In this paper, we design, construct and characterize a 6-mode, 7-core multicore fiber amplifier supporting 42 spatial channels, which represents the highest spatial density SDM amplifier reported to date. An erbium-doped 6-mode 7-core fiber was designed and fabricated to match with a previously fabricated passive transmission fiber [13] and a fully fiberized amplifier was subsequently constructed in a cladding-pumped configuration. By employing a passive cooling system and a high efficiency pump combiner, we achieve a power reduction factor of 0.36 , which as far as we are aware is the lowest value

K, Shibahara, T. Mizuno, Y. Miyamoto are with the NTT Network Innovation Laboratories, NTT Corporation 1-1, Hikari-no-oka, Yokosuka, Kanagawa, Japan (e-mail: kouki.shibahara.nv@hco.ntt.co.jp, takayuki.mizuno.zp@hco.ntt.co.jp, yutaka.miyamoto.fb@hco.ntt.co.jp).

Y. Sasaki is with the Fujikura Optical Technologies R\&D Center, Fujikura Ltd., 1440, Mutsuzaki Sakura, Chiba, Japan (e-mail: yusuke.sasaki@jp.fujikura.com).

K. Saitoh is with the Graduate School of Information Science and Technology, Hokkaido University, Sapporo, Japan, (e-mail: ksaitoh@ist.hokudai.ac.jp).

Color versions of one or more of the figures in this paper are available online at http://ieeexplore.ieee.org.

Digital Object Identifier XX.XXXX/JLT.2016.XXXXXXX 


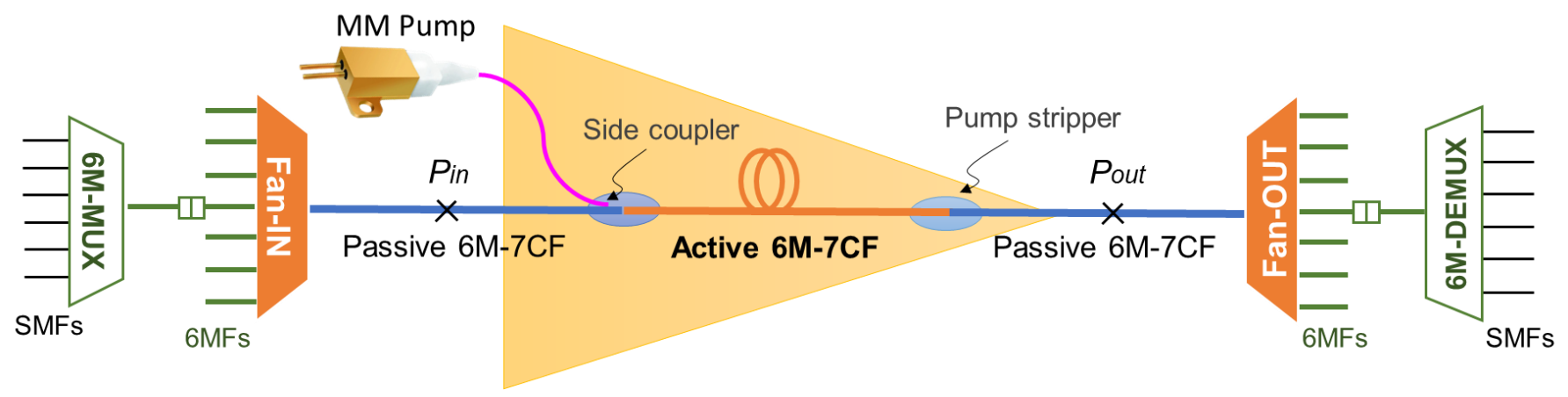

Fig. 1. Schematic of the 6-mode 7-core multicore fiber (6M-7CF) amplifier. 6M-(DE)MUX: 6-mode multiplexer/demultiplexer, MM Pump: multimode pump laser diode, SMF: single mode fiber, 6MFs: 6-mode fibers, 6M-7CF: 6-mode 7-core fiber.

so far reported in a cladding pumped SDM amplifier. We also experimentally demonstrated in-line amplified SDM data transmission over $60 \mathrm{~km}$ of FM-MCF for the first time to the best of our knowledge.

\section{AMPLIFIER CONFIGURATION AND OPTICAL PERFORMANCE}

Fig. 1 shows a schematic of the 6-mode 7-core multicore fiber (6M-7CF) amplifier supporting 42 spatial channels (i.e. 7-core fiber, each of which operated on 6 spatial modes: $\mathrm{LP}_{01}, \mathrm{LP}_{11 \mathrm{a}}, \mathrm{LP}_{11 \mathrm{~b}}, \mathrm{LP}_{21 \mathrm{a}}, \mathrm{LP}_{21 \mathrm{~b}}$ and $\mathrm{LP}_{02}$ ). The amplifier consists of a length of active gain fiber (i.e. a double-clad erbium-doped $6 \mathrm{M}-7 \mathrm{CF}$ for cladding pumping) which is directly spliced to its matched passive multicore fiber counterpart at both ends and is pumped by a multimode pump laser diode $(\lambda=975 \mathrm{~nm}$, power conversion efficiency 50\%, IPG Photonics’ PLD-975-70-WS) [14]. A serial arrangement of multicore fan-in/fan-out devices and mode (de)multiplexers (i.e. a fiber bundle type fan-in/fan-out [15] and multiple lightwave conversion type mode (de)multiplexer [16]) is used at each end of the amplifier to connect the multiple spatial channels from the erbium-doped $6 \mathrm{M}-7 \mathrm{CF}$ to multiple single mode input and output fibers. In order to realize a cost-effective SDM amplifier a cladding pumped approach was used in our amplifier and an all-fiber tapered side pump coupler (incorporated directly onto the active $6 \mathrm{M}-7 \mathrm{CF}$ ) was used to couple multimode pump light into the inner cladding of the active fiber (coupling efficiency $95 \%$ ). Note that the efficiency of the pump coupler was significantly improved relative to our previous demonstration [17] from $60 \%$ to $95 \%$ and it enabled us to obtain higher gain at short wavelengths and to increase the pump conversion efficiency of our amplifier. A pump stripper (based on appropriate application and passive cooling of a high refractive index UV-curable acrylate polymer) was introduced at the other end of the gain fiber to dump the residual unabsorbed pump light. The pump stripper can handle up to $\sim 20 \mathrm{~W}$ of unabsorbed pump light without damage. Importantly, we have incorporated a passive air cooling system (i.e. simple air cooling with forced convection instead of thermoelectric cooling) to dissipate heat from the pump laser diode and $\sim 3 \mathrm{~W}$ energy reduction was successfully achieved compared to [17]. Under passive cooling, the pump wavelength of the multimode laser diode was stably locked (at $\lambda=975 \mathrm{~nm}$ ) due to the built-in volume Bragg grating. Most of pump energy (>99.5\%) was at the Bragg wavelength with a $20 \mathrm{~dB}$ linewidth of $1.0 \mathrm{~nm}$ and the center wavelength was only shifted by $\sim 0.3 \mathrm{~nm}$ when increasing the pump power up to $30 \mathrm{~W}$. We have also tested the long-term stability of our passive cooling system by monitoring the temperature change of the pump LD at the top of the housing and a good thermal equilibrium temperature was achieved $\left(\sim 30.2{ }^{\circ} \mathrm{C}\right.$ at $20 \mathrm{~W}$ and $\sim 34.4{ }^{\circ} \mathrm{C}$ at $30 \mathrm{~W}$ of pump power). By adopting these measures (high efficiency pump pumper and passive air cooling system), we achieved a power reduction factor of 0.36 (versus 0.6 in [10]) as shown in Table 1, which is a new record amongst the claddingpumped MCF amplifiers so far reported. Here, the power reduction factor is defined by considering the total electrical power consumption of the pump laser diode (A), and the cooling power (B) and comparing this with the electrical power consumption of multiple conventional erbium doped fiber amplifiers $(C)$ (i.e. the power reduction factor is defined as $(\mathrm{A}+\mathrm{B}) / \mathrm{C})[10,18]$. In conventional single-mode L-band EDFAs, $>400 \mathrm{~mW}$ optical pump power is required to provide $\sim 20 \mathrm{dBm}$ of saturated output power and a $3.4 \mathrm{~W}$ of total electric power (estimated from JDSU, S28-xxxx-40) is assumed in our comparison [19]. Note that it does not include the power consumption of the amplifier monitoring and management electronics and we are comparing our amplifier with multiple single mode EDFAs with active cooling using a thermo-electric cooler (TEC).

TABLE 1 ELECTRIC POWER REDUCTION FACTOR OF OUR 6M7CF AMPLIFIER.

\begin{tabular}{|c|c|c|c|}
\hline Amplifier type & $\begin{array}{l}\text { (A) Electric } \\
\text { power for LD } \\
{[\mathrm{W}]}\end{array}$ & $\begin{array}{c}\text { (B) Cooling } \\
\text { power [W] }\end{array}$ & $\begin{array}{c}\text { Power } \\
\text { reduction } \\
\text { factor }\end{array}$ \\
\hline $\begin{array}{c}\text { Single-mode L-band } \\
\text { EDFA }\end{array}$ & 1.8 & 1.6 & 1.0 \\
\hline $\begin{array}{c}\text { Our L-band 6-mode } \\
\text { 7-core EDFA }\end{array}$ & 45 & 6 & 0.36 \\
\hline
\end{tabular}


The active 6M-7CF was fabricated in-house using a stackand-draw technique from an erbium-doped preform with a step-index, uniformly doped core. Note that, for our active fiber fabrication, a simple homogeneous core arrangement was employed for ease of fiber fabrication. The detailed fiber geometry and specification of the fabricated fiber is summarized in Fig. 2(a). The core pitch of the active fiber was about $44 \mu \mathrm{m}$, which was closely matched to that of the passive fiber $(44.4 \mu \mathrm{m})$. The core diameter was $\sim 12.5 \mu \mathrm{m}$ to ensure reliable 6 spatial mode operation. However, the higher numerical aperture cores in the active fiber resulted in a large mode field diameter mismatch with the passive fiber and consequently a mode dependent splice loss was observed ( $\sim 0.2 \mathrm{~dB}$ for $\mathrm{LP}_{01}, 1.6 \mathrm{~dB}$ for $\mathrm{LP}_{11}$ and $1.8 \mathrm{~dB}$ for the $\mathrm{LP}_{21} \& \mathrm{LP}_{02}$ modes, respectively). Light from an incoherent white light source (with an incident large beam diameter) was launched into the inner cladding of the active fiber and the small signal cladding absorption spectrum was measured using the cutback method with the aid of an optical spectrum analyzer. The measured small signal cladding absorption was $\sim 0.62 \mathrm{~dB} / \mathrm{m}$ at the absorption peak of $978 \mathrm{~nm}$.

\begin{tabular}{|c|c|c|}
\hline & Passive 6M-7CF & Active 6M-7CF \\
\hline $\begin{array}{c}\text { Cross- } \\
\text { sectional } \\
\text { images }\end{array}$ & $44.4 \mu \mathrm{m}$ & $44 \mu \mathrm{m}$ \\
\hline Core pitch & $23.6 \mu \mathrm{m}$ & $12.5 \mu \mathrm{m}$ \\
\hline Core dia. & $172 \mu \mathrm{m}$ & $175.5 \mu \mathrm{m}$ \\
\hline $\begin{array}{c}\text { Cladding } \\
\text { dia. }\end{array}$ & $1.4 \%$ \\
\hline$\Delta$ & Core $+0.7 \% /$ trench $-0.7 \%$ & \\
\hline
\end{tabular}

(a)

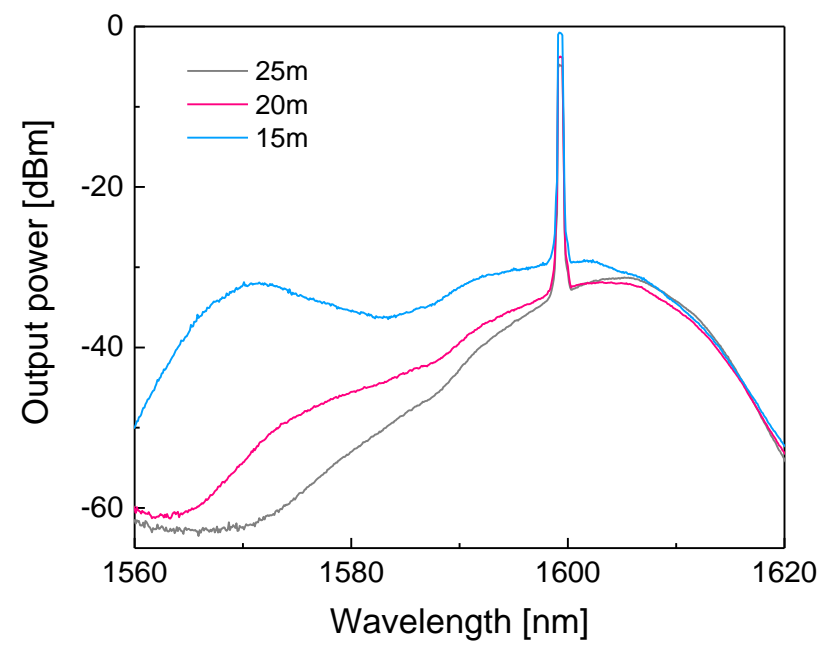

(b)
Fig. 2. (a) Specification of the active $6 \mathrm{M}-7 \mathrm{CF}$ and matching passive transmission fiber and (b) the shift in ASE spectra with different Er-doped fiber lengths for the center core.

In order to optimize the active fiber length, the center core (\#7) was first monitored to evaluate the gain and amplified spontaneous emission (ASE) spectrum. As shown in Fig. 2(b), the ASE spectrum depends on the length of the active fiber and the ASE peak shifts to shorter wavelengths with reduced fiber length at a fixed signal power $(0 \mathrm{dBm}$ per mode at $1600 \mathrm{~nm})$ and pump power $(6.2 \mathrm{~W})$. With a $15 \mathrm{~m}$ length of active fiber, we can achieve good L-band amplifier performance with a good gain flatness. After these initial tests, the complete performance of the 6M-7CF amplifier was characterized using multi-wavelength signals (8 WDM channels in the wavelength range 1570-1605 nm) [20]. Fiber bundle type multicore fan-in/fan-out devices and modeselective mode (de)multiplexers (having a modal purity $>10$ $15 \mathrm{~dB}$ ) were used to access/evaluate the characteristics of each mode within the 7 cores of the $6 \mathrm{M}-7 \mathrm{CF}$ amplifier. The input signal power was $-3 \mathrm{dBm}$ per mode/core and the injected pump power was $22.5 \mathrm{~W}$. The internal gains and noise figures of all spatial channels were measured, and the results are plotted in Fig. 3(a). The majority of the cores exhibit very similar performance with an average gain of $23.1 \mathrm{~dB}$ and a noise figure (NF) of $7.5 \mathrm{~dB}$ with a $<3 \mathrm{~dB}$ spectral variation and a $<2 \mathrm{~dB}$ core-to-core variation across the $35 \mathrm{~nm}$ waveband measured. Note that the spectral gain flatness is significantly improved by more than $3 \mathrm{~dB}$ compared with ref. [17], which is mainly due to the enhanced coupling efficiency of the pump side coupler used. The NFs at longer wavelengths are about 6-7 $\mathrm{dB}$ although these gradually increased toward shorter wavelengths. This is a general feature of the cladding pumped amplifier and is mainly due to the lower population inversion and reabsorption along the active fiber. Our 6M-7CF amplifier can provide more than $17.5 \mathrm{dBm}$ of output power per core per mode (typically nearer $20 \mathrm{dBm}$ for $\mathrm{LP}_{01}$ ). Note that the amplifier characteristics of the $\mathrm{LP}_{21}$ and $\mathrm{LP}_{02}$ modes were evaluated as a single mode group considering the degeneracy of modes in the passive transmission fiber. The differential modal gains (DMGs) for each individual core were also tested and are plotted in Fig. 3(b). As expected in a simple step-index, uniform doped fiber, the lower order modes $\left(\mathrm{LP}_{01}\right.$ and $\left.\mathrm{LP}_{11}\right)$ have higher gain than the higher order modes $\left(\mathrm{LP}_{21}\right.$ and $\mathrm{LP}_{02}$ ) and the maximum DMG was observed to be $\sim 6$ $\mathrm{dB}$. Note that this gain variation includes two imperfect splice points between the passive and active fibers. Each splice currently has a mode dependent splice loss of $\sim 1.6 \mathrm{~dB}$ and the intrinsic internal amplifier performance is expected to be significantly better. 


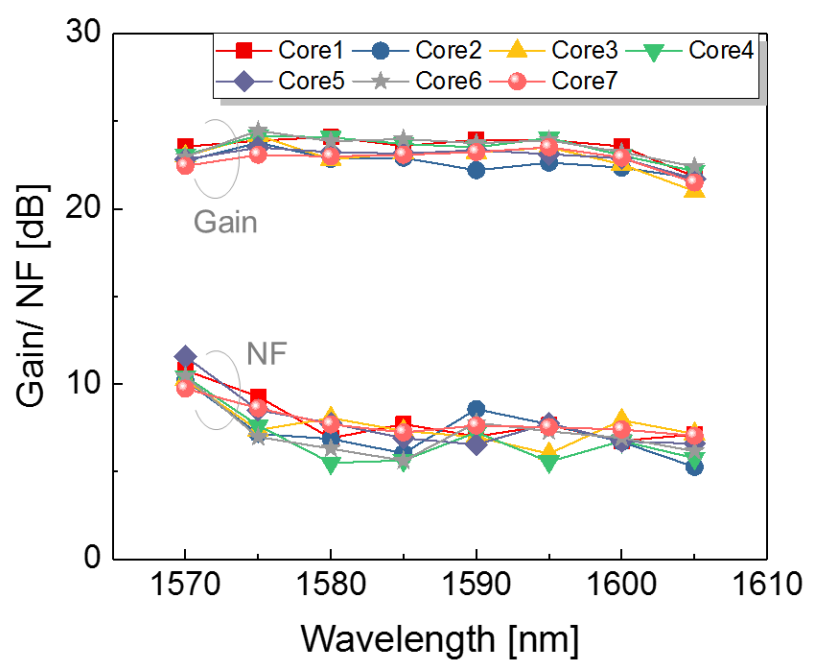

(a)

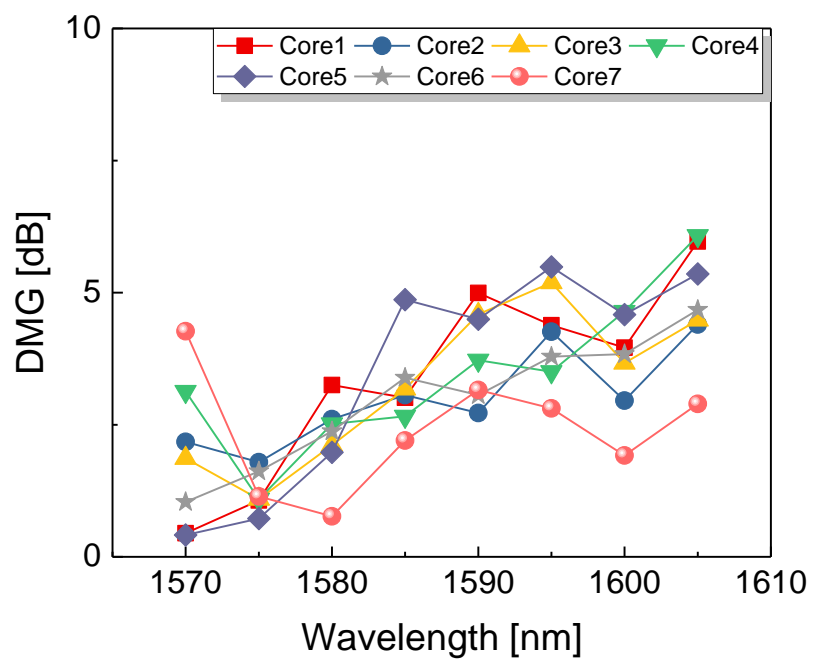

(b)

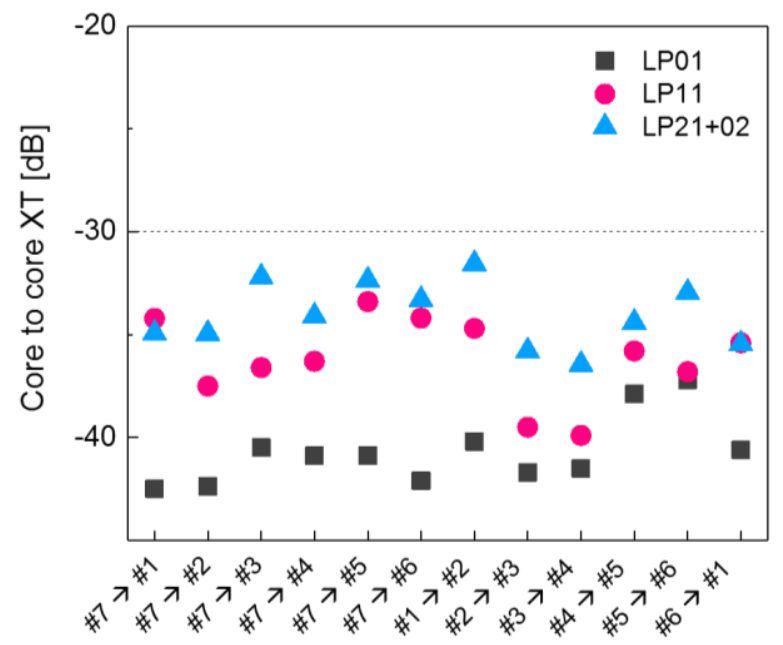

(c)

Fig. 3. (a) Averaged gain and noise figure performance of the $6 \mathrm{M}-7 \mathrm{CF}$ amplifier, (b) mode dependent gain and (c) inter-core crosstalk characteristics at $1600 \mathrm{~nm}$.
Another important characteristics of the few-mode multicore fiber amplifier is the mode dependent intercore crosstalk (XT) and the multi-wavelength XT measurement technique [21] was used in our experiment to monitor the XT between two neighboring cores. Multiple closely spaced wavelength signals around $1600 \mathrm{~nm}$ were injected into the individual spatial modes of the core under test (e.g. core \#1) and the adjacent cores (e.g. core \#2, \#6 or \#7) at different modes were examined by observing the output spectra using an optical spectrum analyzer. As shown in Fig. 3(c), the average core-to-core crosstalk was $-40.6 \mathrm{~dB}$ for the $\mathrm{LP}_{01}$, $-36.1 \mathrm{~dB}$ for the $\mathrm{LP}_{11}$ and $-33.9 \mathrm{~dB}$ for the $\mathrm{LP}_{21} \& \mathrm{LP}_{02}$ modes, respectively. As expected, larger XT was observed for higher order modes due to their large mode field diameters but the measured crosstalk was sufficiently low $(<-30 \mathrm{~dB})$ for all spatial modes. Note that this is the overall amplifier XT value for the amplifier test setup (e.g. including XT from the fan-in/fan-out device) and the inherent amplifier $\mathrm{XT}$ is hence much smaller. The theoretically calculated inherent XT of our active fiber is less than $-70 \mathrm{~dB} / \mathrm{km}$ at $1600 \mathrm{~nm}$.

\section{SimultaneOUSLY AMPLIFIED 6-MODE 7-CORE FIBER TRANSMISSION}

We constructed an inline simultaneously amplified 6mode 7-core MCF transmission system as shown in Fig. 4. The signal wavelengths were $1570.41,1585.36$ and 1600.60 $\mathrm{nm}$. A polarization multiplexed 2-Gbaud QPSK signal was generated at the transmitter and divided into six parts. These six signals were then multiplexed by a 6 -mode multiplexer and fed into a test core through a fan-in device. The other 6mode multiplexed signals were used as dummy channels and were input into the remaining 6 cores of the MCF with the same total input power as the signals under test. All signals were de-correlated using delay lines with different time delays for each core and mode. The transmission line was a fully fiberized SDM link consisting of 27 and $33 \mathrm{~km}$ long lengths of 6M-7CF [13] and the in-line 6M-7CF amplifier which was directly fusion spliced into the transmission line. The propagation losses, differential mode delay and core-tocore crosstalk of the $6 \mathrm{M}-7 \mathrm{CF}$ in the L-band were less than $0.21 \mathrm{~dB} / \mathrm{km}, 0.50 \mathrm{~ns} / \mathrm{km}$ and $-21 \mathrm{~dB} / 100 \mathrm{~km}$ for all modes, respectively.

After transmission, the signals were then de-multiplexed using a fan-out device and 6-mode de-multiplexer and detected by the coherent receivers. We recovered the signals by $12 \times 12$ MIMO processing with time domain equalization. Fig. 5 shows the Q-factors of the received signals after $60 \mathrm{~km}$ long transmission. Here we optimized the input power for each mode in the range -8 to $-3 \mathrm{dBm} /$ mode/core to improve the worst Q-factor between the signals. We successfully confirmed that the Q-factors of all received signals exceeded the $20 \%$-overhead forward error correction (FEC) limit of $5.7 \mathrm{~dB}[22]$. 


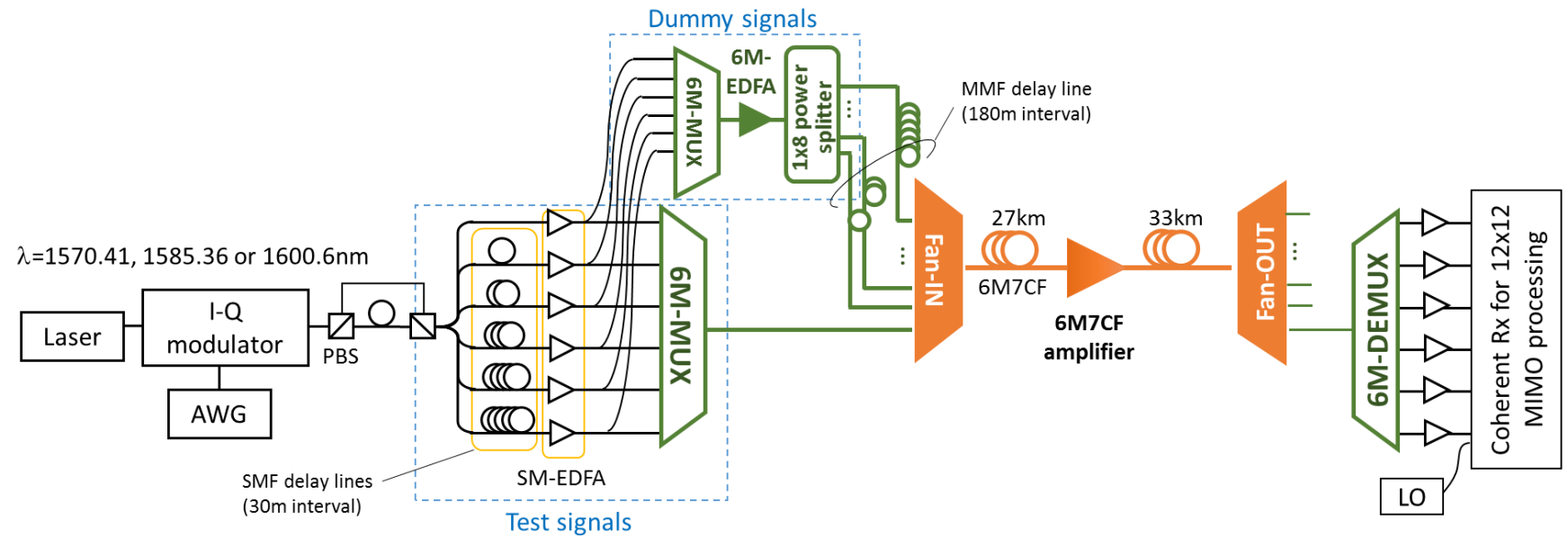

Fig. 4. Experimental setup for simultaneous amplified 6-mode 7-core MCF transmission line $(27+33 \mathrm{~km})$ with an inline $6 \mathrm{M}-7 \mathrm{CF}$ amplifier. AWG: arbitrary waveform generator, PBS: polarization beam splitter, LO: local oscillator, Rx: receiver, MIMO: multi-input multi-output.

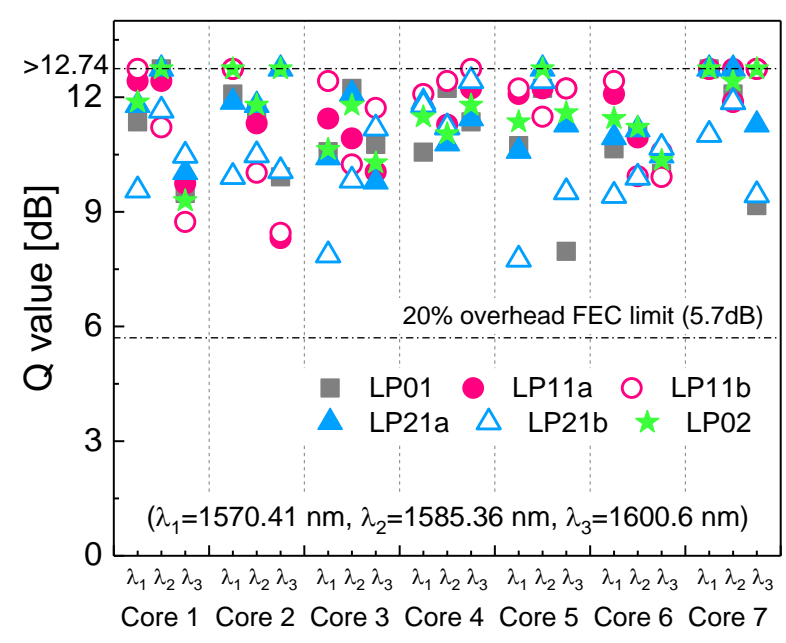

Fig. 5. Q-factors of the received signals after $60 \mathrm{~km} 6 \mathrm{M}-7 \mathrm{CF}$ transmission.

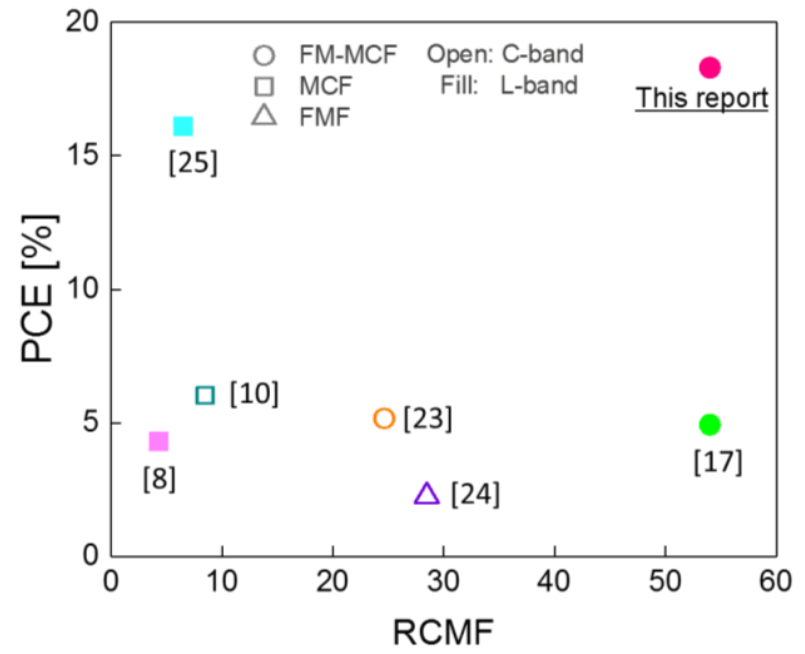

Fig. 6. PCE vs RCMF of the proposed amplifier compared to previously reported SDM amplifier results.
Finally, we evaluated our transmission system in terms of the spatial and energy efficiency. We consider the power conversion efficiency (PCE) which indicates the power conversion efficiency from the pump power and average amplified signal power [10, 16, 23-25], and spatial efficiency through the relative core multiplicity factor (RCMF) [26]. Fig. 6 reveals that our $6 \mathrm{M}-7 \mathrm{CF}$ amplifier can simultaneously achieve the highest PCE and RCMF and that it is highly beneficial for realizing power efficient high density SDM transmission system.

\section{CONCLUSION}

In conclusion, a fully integrated 6-mode 7-core multicore fibre amplifier has successfully been realized in a claddingpumped configuration. The amplifier provided an averaged gain of $23.1 \mathrm{~dB}$ and a noise figure $<7.5 \mathrm{~dB}$ with $<3 \mathrm{~dB}$ spectral variation in the L-band. The average differential modal gain was measured to be $\sim 3.2 \mathrm{~dB}$ (maximum of $6 \mathrm{~dB}$ ) and the amplifier output power was $>17.5 \mathrm{dBm} /$ core/mode. The amplifier is capable of providing simultaneous amplification of 42 spatial channels in a single device (a record multiplicity) and significant cost/space/energy benefits are ultimately to be expected relative to the use of 42 individual EDFAs. Also, we have successfully demonstrated the first simultaneously amplified FM-MCF transmission experiment and achieved the highest spatial and energy efficiencies for a fully integrated SDM transmission link.

\section{REFERENCES}

[1] D. J. Richardson, J. M. Fini and L. E. Nelson, "Space-division multiplexing in optical fibres," Nat. Photonics, vol. 7, pp. 354-362, Apr. 2013.

[2] P. J. Winzer, "Making spatial multiplexing a reality," Nat. Photonics, vol. 8, pp. 345-348, Apr. 2014. 
[3] G. Li, Neng Bai, Ningbo Zhao, and Cen Xia, "Space-division multiplexing: the next frontier in optical communication," Adv. Opt. Photon., vol. 6, pp. 413-487, Dec. 2014.

[4] K. Saitoh and S. Matua, "Multicore fiber technology," J. Lightwave Technol., vol. 34, no. 1, pp. 55-66, Jan. 2016.

[5] K. Igarashi, D. Souma, Y. Wakayama, K. Takeshima, Y. Kawaguchi, T. Tsuritani, I. Morita, and M. Suzuki, "114 space-divisionmultiplexed transmission over 9.8-km weakly-coupled-6-mode uncoupled-19-core fibers," in Proc. OFC, 2015, Th5C.4.

[6] J. Sakaguchi, W. Klaus, J. M. D. Mendinueta, B. J. Puttnam, R. S. Luís, Y. Awaji, N. Wada, T. Hayashi, T. Nakanishi, T. Watanabe, Y. Kokubun, T. Takahata, and T. Kobayashi, "Large spatial channel (36 core $\times 3$ mode) heterogeneous few-mode multicore fiber," $J$. Lightwave Technol., vol. 34, pp. 93-103, Jan. 2016.

[7] T. Sakamoto, K. Saitoh, S. Saitoh, Y. Abe, K. Takenaga, A. Urushibara, M. Wada, T. Matsui, K. Aikawa, K. Nakajima, "120 spatial channel few-mode multi-core fibre with relative core multiplicity factor exceeding 100," in Proc. ECOC, 2018, We3E.5.

[8] H. Chen, C. Jin, B. Huang, N. K. Fontaine, R. Ryf, K. Shang, N. Gregoire, S. Morency, R. -J. Essiambre, G. Li, Y. Messaddeq and S. LaRochelle, "Integrated cladding-pumped multicore few-mode erbium-doped fibre amplifier for space division multiplexed communications," Nat. Photonics, vol. 10, pp. 529-533, Jul. 2016.

[9] Y. Amma, T. Hosokawa, H. Ono, K. Ichii, K. Takenaga, S. Matsuo, and M. Yamada, "Ring-core multicore few-mode erbium doped fiber amplifier," IEEE Photon. Technol. Lett., vol. 29, no. 24, pp. 21632166, Dec. 2017.

[10] S. Jain, C. Castro, Y. Jung, J. Hayes, R. Sandoghchi, T. Mizuno, Y. Sasaki, Y. Amma, Y. Miyamoto, M. Bohn, K. Pulverer, M. Nooruzzaman, T. Morioka, S. Alam, and D. J. Richardson, "32-core erbium/ytterbium-doped multicore fiber amplifier for next generation space-division multiplexed transmission system," Opt. Express, vol. 25, pp. 32887-32896, Dec. 2017.

[11] Y. Jung, A. Wood, S. Jain, Y. Sasaki, S. Alam, and D. J. Richardson, "Fully integrated optical isolators for space division multiplexed (SDM) transmission," APL Photonics, vol. 4, 022801, Dec. 2018.

[12] K. S. Abedin, J. M. Fini, T. F. Thierry, B. Zhu, M. F. Yan, L. Bansal, F. V. Dimarcello, E. M. Monberg, and D. J. DiGiovanni, "Seven-core erbium-doped double-clad fiber amplifier pumped simultaneously by side-coupled multimode fiber," Opt. Lett., vol. 39, pp. 993-996, Feb. 2014.

[13] T. Sakamoto, K. Saitoh, S. Saitoh, K. Shibahara, M. Wada, Y. Abe, A. Urushibara, K. Takenaga, T. Mizuno, T. Matsui, K. Aikawa, Y. Miyamoto, and K. Nakajima, "Six-mode seven-core fiber for repeated dense space-division multiplexing transmission," $J$. Lightwave Technol., vol. 36, no. 5, pp. 1226-1231, Mar. 2018.

[14] https://pdf.directindustry.com/pdf/ipg-photonics-corporation/pld-70laser-diode/29249-679493.html

[15] Y. Abe, K. Shikama, S. Yanagi and T. Takahashi, "Low-loss physical-contract-type fan-out device for 12-core multicore fiber," in Proc. ECOC, 2013, P.1.7.

[16] G. Labroille, B. Denolle, P. Jian, P. Genevaus, N. Treps, and J. Morizur, "Efficient and mode selective spatial mode multiplexer based on multi-plane light conversion," Opt. Express, vol. 22, pp. 15599-15607, Jun. 2014.

[17] Y. Jung, M. Wada, T. Sakamoto, S. Jain, I. A. Davidson, P. Barua, J. R. Hayes, S. Alam, K. Nakajima, and D. J. Richardson, "High spatial density 6-mode 7-core multicore L-band fiber amplifier," in Proc. OFC, 2019, Th1B. 7.

[18] K. Takeshima, T. Tsuritani, Y. Tsuchida, K. Maeda, T. Saito, K. Watanabe, T. Sasa, K. Imamura, R. Sugizaki, K. Igarashi, I. Morita, and M. Suzuki, "51.1-Tbit/s MCF Transmission Over $2520 \mathrm{~km}$ Using Cladding-Pumped Seven-Core EDFAs," J. Lightwave Technol., vol. 34, no. 2, pp. 761-767, Jan. 2016.

[19] https://manualzz.com/doc/8156234/datasheet-for-s28-7402-300-byjds-uniphase-corporation

[20] M. Wada, S. Jain, K. Shibahara, Y. Jung, I. A. Davidson, P. Barua, J. R. Hayes, T. Sakamoto, T. Mizuno, Y. Miyamoto, D. J. Richardson, Y. Sasaki, K. Saitoh, and K. Nakajima, "High density few-mode multicore fibre amplifier for energy efficient SDM transmission," in Proc. ECOC, 2019, W.2.C.1.

[21] Y. Tsuchida, K. Maeda, Y. Mimura, H. Matsuura, R. Miyabe, K. Aiso, and R. Sugizaki, "Amplification characteristics of a multi-core erbium-doped fiber amplifier," in Proc. OFC, 2012, OM3C.3.
[22] D. Chang, F. Yu, Z. Xiao, N. Stojanovic, F.N. Hauske, Y. Cai, C. Xie, L. Li, X. Xu, and Q. Xiong, "LDPC convolutional codes using layered decoding algorithm for high speed coherent optical transmission," in Proc. OFC, 2012, OW1H.4.

[23] M. Wada, T. Sakamoto, S. Aozasa, T. Mori, T. Yamamoto and K. Nakajima, "Two-LP-Mode Six-Core Cladding Pumped EDFA With High Pump Power Density," J. Lightwave Technol., vol. 36, no. 2, pp. 331-335, Jan. 2018

[24] N. K. Fontaine, B. Huang, Z. S. Eznaveh, H. Chen, J. Cang, B. Ercan, A. Velaquez-Benitez, S. H. Chang, R. Ryf, A. Schulzgen, J. C. A. Zaharias, P. Sillard, C. Gonnet, J. E. A. Lopez, R. Amezcua-Correa, "Multi-mode optical fiber amplifier supporting over 10 spatial modes," in Proc. OFC, 2016, Th5A.4.

[25] S. Takasaka, K. Maeda, K. Kawasaki, K. Yoshioka, H. Oshio, R. Sugizaki, Y. Kawaguchi, H. Takahashi, T. Tsuritani, and M. Shiino, "Increase of cladding pump power efficiency by a 19-core erbium doped fibre amplifier," in Proc. ECOC, 2017, Th2D

[26] K. Takenaga, Y. Arakawa, Y. Sasaki, S. Tanigawa, S. Matsuo, K. Saitoh, and M. Koshiba, "A large effective area multi-core fiber with an optimized cladding thickness," Opt. Express, vol. 19, pp. B543B550, Nov. 2011. 